\title{
Interactive comment on "How warm was Greenland during the last interglacial period?" by Amaelle Landais et al.
}

\section{Anonymous Referee \#1}

Received and published: 26 April 2016

Review: "How warm was Greenland during the last interglacial period?" by Amaelle Landais et al.

The manuscript looks at $\mathrm{d} 15 \mathrm{~N}$ evidence, to help determine the peak LIG (Last Interglacial) temperature across Greenland. This is an important question, with implications for the resilience of the Greenland ice sheet to future temperature rise. The manuscript is mostly well written and structured. However, I have a few reservations about the way the $\mathrm{d} 15 \mathrm{~N}$ evidence is presented.

Major points:

p11 It is very interesting that the NEEM and NGRIP d15N reconstructions at $120 \mathrm{ka}$ are so different: +8.5 versus $+3.2 \mathrm{C}$. This merits more analysis and attention. In particular, is the 120 ka NGRIP is less affected by uncertainty generated by melt processes? 
This should be mentioned in the conclusions and in the abstract. Moreover the likely reasons for this discrepancy should be subject to further investigation/discussion and emphasis within this manuscript.

p12 L7-9 Have the studies by Metz et al not already provided enough information to attempt to constrain these 'other influences' on surface temperature and accumulation rates? And if so, should this not be included within the analysis/uncertainties for this study?

Minor points:

p6-7 section 3.1 This text could be clarified. It could be made easier for the reader to follow whether the reconstructions relate to the LIG or the Holocene.

p8 L22-23 "must not necessarily hold back in time" rephrase.

p9 L25 Capitalisation.

p11 L11-12 120ka is considerably later than the NEEM peak temperature, it could be made clear to the reader which different times in the LIG the reconstructions relate to, particularly the NEEM versus NGRIP.

p11 L31 Would be useful to have a brief description of the 'other advective pathways'.

p11 L42 "We hope?" shall motivate further studies?

p12 L1-4 I find this description of which further studies are required particularly useful.

p12 'sharp signal' rephrase?

p12 L14 16m? And perhaps clarify/rephrase 'a dominant influence of surface melt of about 16m'.

Printer-friendly version

p12 L15- 37 This is a very nice summary review or relevant GCM studies.

P14 L24-25 "The evidence of summer melt at the LIG section of the NEEM core also stresses the intrinsic limitations of our approach." As above, this sentence/point could

Interactive

comment

$\mathrm{C} 2$

Discussion paper

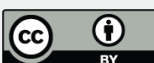


be rewritten to emphasise the actual uncertainties associated with the d15N-based temperature estimates.

CPD

Interactive comment on Clim. Past Discuss., doi:10.5194/cp-2016-28, 2016.

Interactive

comment 